\title{
Long-term result of endoscopic treatment of an ampullary adenoma with extension into the common bile duct
}

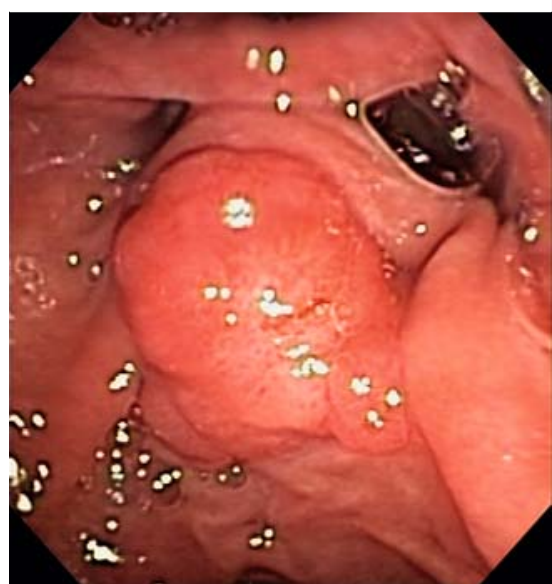

Fig. 1 Endoscopic image showing a lesion at the major papilla.

A 56-year-old man with chronic hepatic disease due to hepatitis $C$ and esophageal varices was referred to our hospital with an elevated alpha-fetoprotein level and a solid lesion in the distal common bile duct (CBD) seen on computed tomography (CT) scanning. This lesion was protruding into the second part of the duodenum and causing dilatation of the biliary tree. An upper gastrointestinal endoscopy revealed a raised lesion at the major duodenal papilla ( $\mathbf{F i g . 1 )}$ ). Biopsies showed a tubular adenoma with low grade dysplasia. Endoscopic ultrasound (EUS) revealed thickening that was restricted to the mucosal layer and choledocholithiasis.

The patient was not suitable for surgical treatment because of his portal hypertension. We therefore performed an endoscopic papillectomy, followed by a sphincterotomy and placement of a plastic pancreatic stent. A follow-up endoscopy 7 days later revealed a residual lesion with a filling defect in the distal CBD (\$ Fig.2). After 30 days, a cholangioscopy was performed using $\mathrm{CO}_{2}$ and a pediatric gastroscope passed over a guidewire ( Fig.3). Biopsies were taken and the residual lesion was treated with

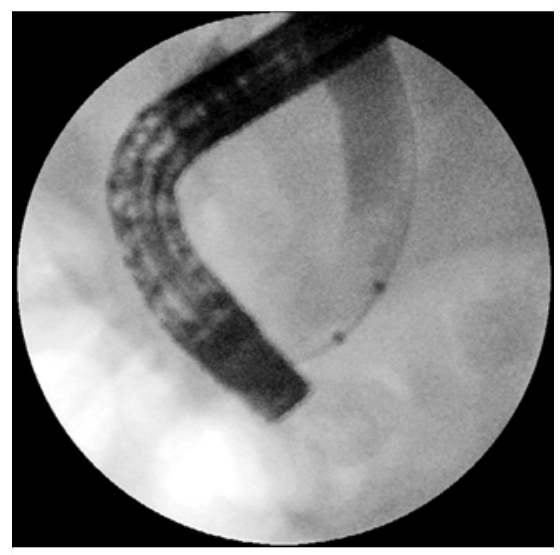

Fig. 2 Cholangiogram performed 7 days after the initial therapy showing an irregular filling defect in the distal common bile duct.

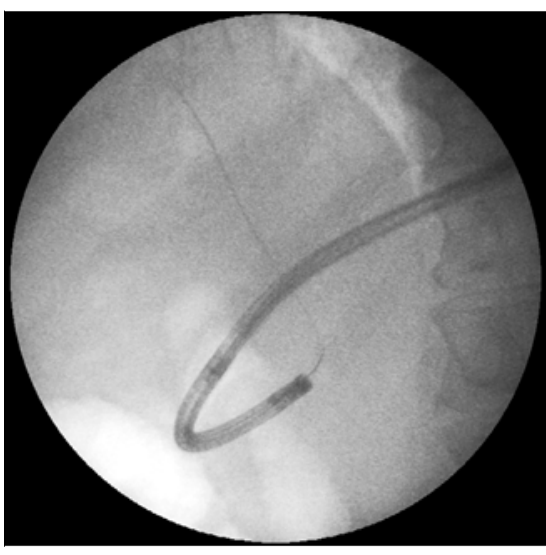

- Fig. 3 Radiographic image during cholangioscopy performed with a pediatric gastroscope passed over a guidewire.

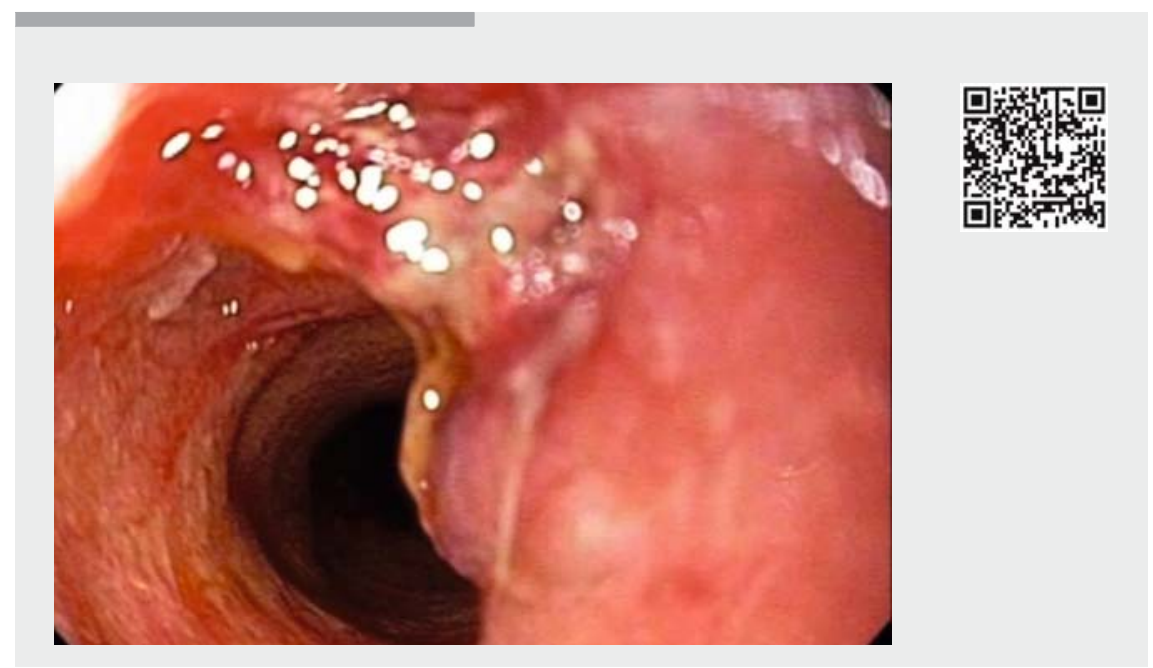

$\checkmark$ Video 1 Cholangioscopy performed after papillectomy with a pediatric slim gastroscope revealed a residual lesion in the distal common bile duct. Biopsies were taken and the residual lesion was treated with argon plasma coagulation (APC).

argon plasma coagulation (APC) at $20 \mathrm{~W}$ and $1.5 \mathrm{~L} / \mathrm{min}$ ( $\triangleright$ Video 1 ).

The patient remains completely asymptomatic 5 years later, receiving annual follow-up, and having no residual lesions (> Fig.4).

Ampullary adenomas can be found incidentally on endoscopic screening exami- nations and harbor a malignant potential [1]. In a retrospective study, 180 patients who had been treated for ampullary adenomas were followed up for a mean of 4.4 years [2]. There was no difference in endoscopic and operative resection of the ampullary adenomas in terms of local recurrence. However, intraductal 

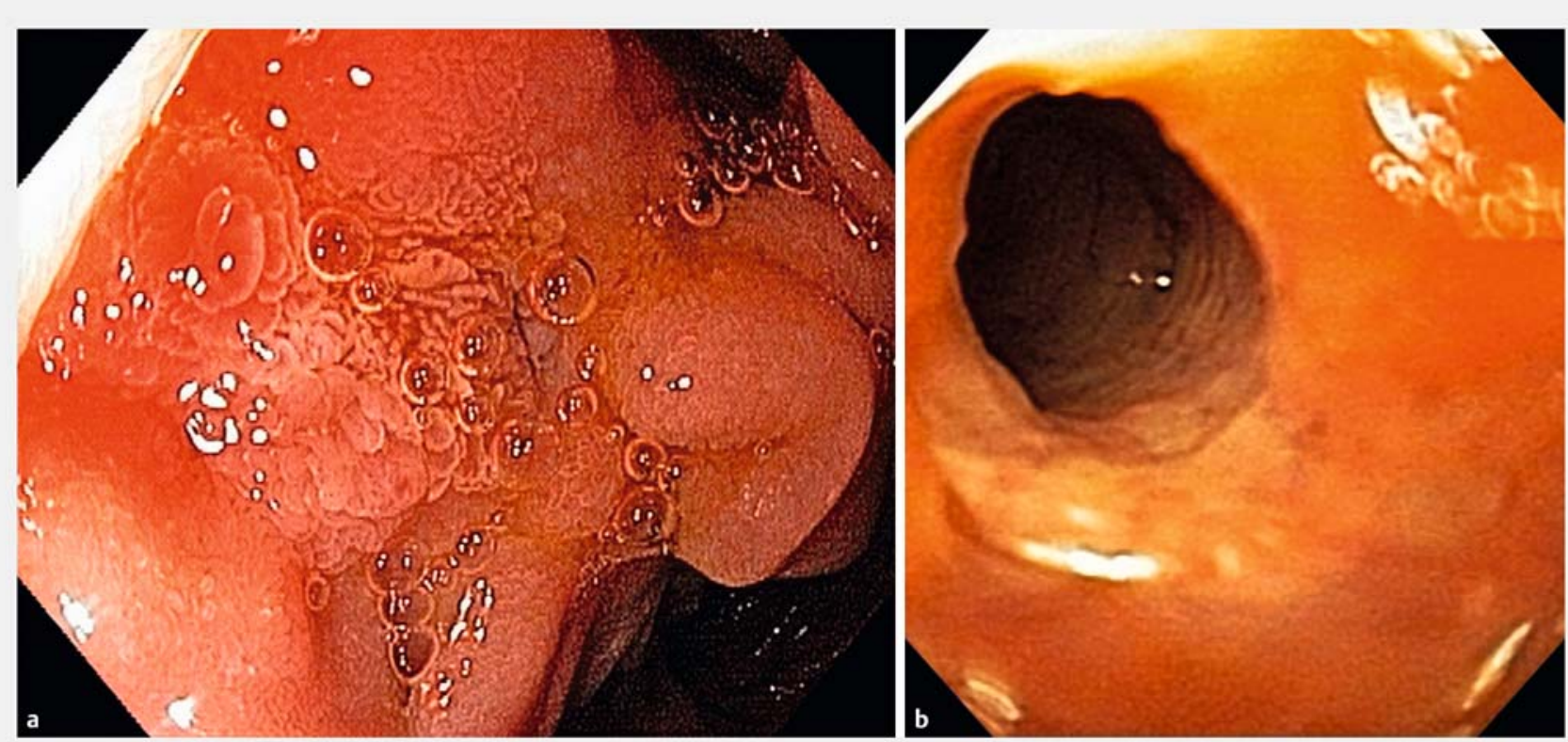

- Fig. 4 Appearances 5 years after treatment on: a endoscopy of the ampullary region; $\mathbf{b}$ cholangioscopy.

extension of an adenoma is recognized as a limitation to endoscopic treatment [3]. In selected cases, intraductal adenomatous tissue can be endoscopically treated by ablation [1]. In our case, direct cholangioscopy with a slim scope and APC proved to be a valuable strategy for ablation of the intraductal adenomatous tissue.

Endoscopy_UCTN_Code_TTT_1AR_2AF

Competing interests

None

The authors

Rodrigo Corsato Scomparin, Luiza Haendchen Bento, Clelma Pires Batista, Marcelo Simas de Lima, Gustavo Andrade de Paulo, Bruno Costa Martins, Fauze Maluf-Filho

Department of Gastroenterology, Division of Endoscopy, Institute of Cancer of São Paulo, University of São Paulo, São Paulo, Brazil
Corresponding author

\section{Rodrigo C. Scomparin, MD}

Institute of Cancer of São Paulo - Division of Endoscopy, University of São Paulo, 251 Dr Arnaldo Avenue, 01246-000 São Paulo, Brazil

Fax: +55-11-38932000

r.scomparin@outlook.com

\section{References}

[1] Chathadi KV, Khashab MA, Acosta RD et al. The role of endoscopy in ampullary and duodenal adenomas. Gastrointest Endosc 2015; 82: 773-781

[2] Onkendi EO, Naik ND, Rosedahl JK et al. Adenomas of the ampulla of Vater: a comparison of outcomes of operative and endoscopic resections. J Gastrointest Surg 2014; 18: $1588-1596$

[3] Bohnacker S, Seitz U, Nguyen D et al. Endoscopic resection of benign tumors of the duodenal papilla without and with intraductal growth. Gastrointest Endosc 2005; 62: $551-560$

\section{Bibliography}

DOI https://doi.org/10.1055/s-0044-100917

Published online: 16.2.2018

Endoscopy 2018; 50: E109-E110

(c) Georg Thieme Verlag KG

Stuttgart · New York

ISSN 0013-726X

\section{ENDOSCOPY E-VIDEOS}

https:/|eref.thieme.de/e-videos

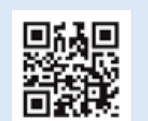

Endoscopy E-Videos is a free access online section, reporting on interesting cases and new techniques in gastroenterological endoscopy. All papers include a high quality video and all contributions are freely accessible online.

This section has its own submission website at

https://mc.manuscriptcentral.com/e-videos 